Center for Policy Impact in Global Health, Duke Global Health Institute Duke University, Durham, North Carolina, USA

2 WHO Health Emergencies Programme, World Health Organization Regional Office for the Eastern Mediterranean, Nasr City, Cairo, Egypt

Correspondence to: G Yamey gavin.yamey@duke.edu

Cite this as: BMJ 2021;375:n2897 http://dx.doi.org/10.1136/bmj.n2897 Published: 25 November 2021

\title{
Preventing pandemics in the world's most vulnerable settings
}

\author{
A global framework convention must include the needs of fragile and conflict affected settings \\ Gavin Yamey, ${ }^{1}$ Kaci Kennedy McDade, ${ }^{1}$ Richard J Brennan, ${ }^{2}$ Abdinasir Abubakar, ${ }^{2}$ Wasiq Khan ${ }^{2}$
}

The covid-19 pandemic has exposed major gaps in national, regional, and global systems of pandemic preparedness and response, including underfunding, weak application of the International Health Regulations (IHR), and global inequities in access to covid-19 vaccines. Several global reports have made recommendations for closing these gaps. ${ }^{12}$ But these reports do not capture the unique context of fragile, conflict affected, and vulnerable (FCV) settings. From 29 November to 1 December 2021 a World Health Assembly special session will discuss the merits of developing a new international instrument (such as a "framework convention") on pandemic preparedness and response. ${ }^{3}$ We call on member states to ensure that the needs of FCV settings are included in these discussions.

These needs matter. There is no "global" preparedness without preparedness in FCV settings, where an estimated one in eight people currently live. ${ }^{4}$ Pandemics can amplify existing political tensions and worsen conflict in these settings, as seen in west Africa in the 2014-16 Ebola epidemic, ${ }^{5}$ and can have catastrophic health and economic effects on these already vulnerable places. Covid-19, for example, pushed an additional 20 million people into extreme poverty in FCV nations. ${ }^{6}$ And the underlying conditions in these settings-such as overcrowding and poor access to water, sanitation, and hygiene-can contribute to "spark risk (where a pandemic is likely to arise) and spread risk (how likely it is to diffuse broadly through human populations)."5

Preparedness is uniquely challenging in FCV settings. A deficit of trust between citizens and leaders, divided territories, and poor joint pandemic planning among many national and international actors all threaten the governance of preparedness. Policy planning and implementation is difficult when the security situation is volatile. Health services, information systems, and infrastructure may have been weakened or destroyed by conflict. Health professionals may have insufficient training or work in unsafe conditions. Sustainable financing from domestic and external sources is lacking, as is funding to purchase pandemic vaccines. Internally displaced people, refugees, migrants, and returnees face heightened risks, in part due to stigma, discrimination, and exclusion from health services. ${ }^{7}$

How can these challenges be tackled? Based on published research, case studies of successful approaches, and field experience, we propose five key actions for consideration.

First, diplomacy should become a central plank of pandemic preparedness and response in FCV settings. Diplomacy to cease hostilities across divided territories has been fruitful in, for example, achieving "vaccination ceasefires" in Afghanistan, Lebanon, and Yemen, and in reaching communities that may be suspicious of outsiders or of pandemic control campaigns.

Second, we need dedicated, long term funding specifically for preparedness, including for core IHR capacities (those "required to detect, assess, notify and report events, and respond to public health risks and emergencies of national and international concern"). Such funding has fallen through the cracks between humanitarian and development donors. Funding should target strengthening and protection of the health workforce and improvement of epidemiological surveillance and laboratory capacities, including early warning and response systems (used in Iraq, Libya, Somalia, Syria, and Yemen $^{8}$ ). National action plans for health security, drawn up following joint external evaluation of a country's capacity to meet international health regulations, ${ }^{9}$ must be fully funded. External financing should be channelled through public systems where possible, strengthening these systems in the process - the ultimate aim should be domestic ownership of pandemic preparedness financing.

Third, action should be taken to strengthen multisectoral governance at regional and community levels and to bolster the governance capacity of non-governmental organisations (NGOs). Experienced frontline NGOs often bring speed, scale, and community knowledge to pandemic preparedness efforts. Engaging communities underpins preparedness and response in FCV settings and has been critical during the covid-19 pandemic for raising awareness, linking local communities with central campaigns, and identifying high risk groups for shielding. Regional governance approaches should be bolstered-their value is clear from successful regional collaborations such as the East Africa Health Laboratory Networking Project for TB control, polio, meningitis, cholera, and yellow fever. ${ }^{10}$

Fourth, while there is widespread interest in a pandemic framework convention, experts working in FCV settings are calling for technical guidance specific to particular types of settings and consistent with on-the-ground realities and available resources. Tailored guidance is needed particularly in settings without a functioning government, where a government or territory is divided, or where there are large numbers of displaced people. For example, where testing capacity for epidemic or pandemic infections is limited, resource stratified guidelines could prioritise targeted tests for at-risk populations and healthcare workers. ${ }^{11}$ 
Fifth, context specific research evaluating preparedness policies, systems, and implementation is urgently needed. Few preparedness responses have been formally evaluated in FCV settings, hindering adaptation and improvement. Biomedical research also has a critical role, given the value of innovations such as low cost rapid diagnostic tests and single dose vaccines in FCV settings. ${ }^{12}$

The forthcoming World Health Assembly provides an opportunity to amplify voices from fragile, conflict affected, and vulnerable settings in discussions of pandemic preparedness. Global preparedness measures that exclude these settings will not be fit for purpose.

Provenance and peer review: Not commissioned; externally peer reviewed.

Competing interests: We have read BMJ policy about conflicts of interest and have the following to declare: KKM has received grant funding for research works from WHO, Gates Foundation, New Venture Fund, Duke University, and the Alliance for Health Systems Policy Research. Through her role at Duke, she has conducted research under subcontracts/grants from SEEK Development and Open Consultants. All other authors have nothing to declare.

1 Independent Panel for Pandemic Preparedness and Response. Covid-19. Make it the last pandemic 2021. https://theindependentpanel.org/wp-content/uploads/2021/05/COVID-19-Make-it-theLast-Pandemic_final.pdf

2 Global Preparedness Monitoring Board. A world prepared. 15 Jun 2021.

https://www.gpmb.org/annual-reports/overview/item/gpmb-strategic-plan-2021-2023

3 World Health Organization. Special session of the World Health Assembly to consider developing a WHO convention, agreement or other international instrument on pandemic preparedness and response. https://apps.who.int/gb/ebwha/pdf_files/WHA74/A74(16)-en.pdf

4 Baier J, Kristensen MB, Davidsen S. Poverty and fragility: where will the poor live in 2030? https://www.brookings.edu/blog/future-development/2021/04/19/poverty-and-fragility-wherewill-the-poor-live-in-2030/

5 Madhav N, Oppenheim B, Gallivan M, et al. Pandemics: risks, impacts, and mitigations. Disease Control Priorities: Improving Health and Reducing Poverty. 3rd edition.

https://www.ncbi.nlm.nih.gov/books/NBK525302/

6 World Bank. Fragility, conflict, and violence. https://www.worldbank.org/en/topic/fragilityconflictviolence/overview\#1

7 World Health Organization. Regional Office for the Eastern Mediterranean. WHO interim guidance note: health system response to covid-19 in the context of internally displaced persons, refugees, migrants and returnees in the Eastern Mediterranean Region. 7 Apr 2020. https://apps.who.int/iris/handle/10665/331943

8 Mala P, Abubakar A, Takeuchi A, etal. Structure, function and performance of Early Warning Alert and Response Network (EWARN) in emergencies in the Eastern Mediterranean Region. Int J Infect Dis 2021;105:194-8. doi: 10.1016/j.ijil.2021.02.002 pmid: 33556613

9 Mghamba JM, Talisuna AO, Suryantoro L, etal. Developing a multisectoral National Action Plan for Health Security (NAPHS) to implement the International Health Regulations (IHR 2005) in Tanzania. BMJ Glob Health2018;3:e000600. doi: 10.1136/bmjgh-2017-000600 pmid: 29607098

10 East African Community. East Africa public health laboratory networking project. https://www.eac.int/health/disease-prevention/east-africa-public-health-laboratory-networkingproject

11 Alawa J, Alawa N, Coutts A, Sullivan R, Khoshnood K, Fouad FM. Addressing COVID-19 in humanitarian settings: a call to action. Confl Health 2020;14:64. doi: 10.1186/s13031-020-00307-8 pmid: 32934662

12 Chadwick S, Townes DA, Perrone LA. Utility of point of care and rapid diagnostics in humanitarian emergencies. J Appl Lab Med 2021;6:236-46. doi: 10.1093/jalm/jfaa180 pmid: 33247297 